Federal Reserve Bank of Minneapolis

Research Department Working Paper

SOME ALTERNATIVE MONETARY MODELS

AND THEIR IMPLICATIONS FOR THE ROLE

OF OPEN-MARKET POLICY

Neil Wallace*

Working Paper 315

Revised April 1987

NOT FOR DISTRIBUTION

WITHOUT AUTHOR'S APPROVAL

*Federal Reserve Bank of Minneapolis and University of Minnesota.

The views expressed herein are those of the author and not necessarily those of the Federal Reserve Bank of Minneapolis or the Federal Reserve System. The material contained is of a preliminary nature, is circulated to stimulate discussion, and is not to be quoted without permission of the author. 
This paper surveys some alternative monetary models from the point of view of their implications for the effects of different open-market policies--different portfolio strategies for a consolidated government-central bank. The models examined share the feature that positive nominal-interest, default-free securities and zero nominal-interest government money can coexist; i.e., there can be rate-of-return dominance of government money. The devices used for generating such rate-of-return dominance are not novel; they are money-in-the-utility-function, cash-in-advance constraints, and legal restrictions. These devices are examined in the context of alternative background intertemporal settings-prototype representative, infinitely-lived agent models and prototype overlapping generations models. Although the above devices for generating return dominance of government money have of ten been criticized, the models I will be surveying continue to be used because they and closely related models seem to be the only ones available that are simple and coherent enough to permit us to describe the welfare consequences of alternative open-market policies. Before I summarize those welfare consequences, it is necessary to describe more precisely the class of policies studied.

In models with rate-of-return dominance, different government portfolio strategies imply different streams of profits on the portfolio or, equivalently, different streams of government interest payments. That being so, a complete description of a policy requires a description of how these profits are used. I will examine different portfolio strategies holding constant real 
government consumption and real direct taxes and, hence, the real net-of-interest deficit. ${ }^{1}$ Among such policies, the higher are earnings on the government's portfolio, the greater the rate of decrease in outstanding government liabilities, and, therefore, through lower inflation, the higher the real return on government money. I focus on this class for several reasons. First, since policies in this class have been studied in only some of the models I survey, some common implications of all the models have not been emphasized. Second, since these policies do not call for adjusting direct taxation, their implementation requires only voluntary exchanges between the government and the public. Third, this class of policies allows the government, through its own lending, to arbitrage between its money and higher yielding assets and, by so doing, drive down the yield differential. ${ }^{2}$ Such arbitrage is an obvious kind of policy to study in these models because it resembles what private agents or intermediaries would do on their own if the models allowed privately issued liabilities to play the role that the models assign to government money--allowed privately supplied liabilities to yield utility, or allowed such liabilities to serve as cash in cash-in-advance models, or did not include legal restrictions.

I further limit policy by imposing two restrictions. First, I impose a nonnegative real net-of-interest deficit, which rules out deflation financed by direct taxation. Second, I assume a positive initial nominal stock of outside money and require that policies be consistent with a positive value of this stock, which is a way of requiring that the existing monetary system be maintained. 
Finally, although this is a volume on business cycles, I will conduct the analysis entirely in terms of stationary and nonstochastic models and stationary policies because such an analysis is sufficient for bringing out the main similarities and differences among the models. As this suggests I will not address questions concerning time consistency, a topic which is dealt with in another essay in this volume.

In all the models examined, a difference between the rate of return on nonmonetary assets and that on money is distorting. In the representative agent models, although utility of the agent is higher the lower is this rate-of-return difference, the above two restrictions do not allow complete elimination of the difference. For such models, I show that policies with some government lending dominate a policy without such lending. The results in overlapping generations models are similar, but less straightforward for two reasons. In those models, policies in the class studied have distribution effects. Also, in them policy effects depend in part on whether or not the model allows steadystate equilibrium interest rates to be nonpositive.

For the class of policies studied here, the qualitative results do not seem to depend on the way rate-of-return dominance is produced in the different models. That should not, however, be taken to mean that how we account for rate-of-return dominance is in general unimportant. For other policy issues, the different models may have quite different implications. Also, the common conclusions concerning the effects of different government portfolios could conceivably be the result of a common flaw in the way 
all the models produce rate-of-return dominance. This matter is taken up briefly in the conclusion.

1. Money, bonds and steady-state seignorege

Many of the results reported below are directly traceable to the possibilities the government has for earning revenue through manipulation of its portfolio. I begin here by discussing such possibilities in terms of the government cash flow constraint and some general features of the steady-state demands for two kinds of government issued liabilities--money and bonds.

I write the government cash flow constraint as

$$
D=p_{t}\left(M_{t+1}-M_{t}\right)+p_{t}\left(S_{t} B_{t+1}-B_{t}\right)
$$

where $D$ is the constant per capita nonnegative real net-of-interest deficit, $p_{t}$ is the price of a unit of money at $t$ in terms of the single time $t$ consumption good, $M_{t}$ is the per capita stock of money at the beginning of date $t, M_{t+1}-M_{t}$ is the time $t$ per capita addition to the stock, $S_{t}$ is the price in terms of money of a bond which is a default free promise to one unit of money at $t+$ 1 so that $s_{t}^{-1}-1$ is the time $t$ nominal interest rate, and $B_{t}$ is the per capita face value in units of time $t$ money of the bonds that mature at date $t$. Throughout, I will take $D$ as given, will let $t=1$ be the initial date, and will treat $M_{1}$ and $B_{1}$ as given initial conditions that satisfy $M_{1}+B_{1}>0$.

$$
\text { Suppose we let } m_{t}=p_{t} M_{t+1} \text { and } b_{t}=p_{t} S_{t} B_{t+1} \text {, the real }
$$
per capita values of money and bonds, respectively, and let $r_{t}^{m}=$ $p_{t+1} / p_{t}$ and $r_{t}=p_{t+1} / p_{t} s_{t}$, the real returns on money and bonds, respectively. Then, constant values of these variables for $t \geq 1$, 
denoted without subscripts, satisfy (1) for all $t \geq 1$ if and only if they satisfy

$$
\begin{aligned}
& D=m+b-p_{1}\left(M_{1}+B_{1}\right) \\
& D=\left(1-r^{m}\right) m+(1-r) b
\end{aligned}
$$

where, for such constant sequences, (2) is equivalent to (1) for $t=1$ and (3) is equivalent to (1) for $t \geq 2$. It follows that such constant values can be a monetary equilibrium only if they satisfy (3) and imply a positive value of $p_{1}$ by way of (2).

In the stationary (no-growth) models that I will discuss, a stationary equilibrium, one in which $m_{t}, b_{t}, r_{t}$, and $r_{t}^{m}$ are constant, is Pareto-optimal if and only if the returns satisfy

$$
r^{m}=r \geq 1 .
$$

The equality in (4) is the familiar condition that the yield on money be equal to the yield on other assets, while the inequality is the familiar condition that the rate of interest be at least as high as the growth rate.

We can quickly draw some conclusions about the possible consistency and inconsistency of (2)-(4) and $p_{1}>0$. The assumptions $D \geq 0$ and $M_{1}+B_{1}>0$ and the requirement $p_{1}>0$ imply, by way of (2), that $m+b>D \geq 0$. These last inequalities and (3) are consistent with (4) only if $r=1$. In the infinitely-lived representative agent models, $r$ exceeds one in a stationary equilibrium, so, as noted above, no policy in the class studied will permit (2)-(4) to be satisfied. Nevertheless, through sufficient government lending, $r-r^{m}$ can be made small. In some versions of overlapping generations models, (2)-(4) are mutually consistent. 
2. Prototype representative, infinitely-lived agent models

For my purpose of drawing out the implications for openmarket operations of different monetary models, it is enough to use quite simple prototype versions of the different models. Here I use what seem to me to be the simplest money-in-the-utility function and cash-in-advance models consistent with equality between returns on money and other assets being necessary for optimality.

\subsection{Money-in-the-utility-function}

Here I use a pure-exchange (no-production) economy in which the representative agent has preferences given by $\sum_{t=1}^{\infty} B^{t} u\left(c_{t}, m_{t}\right)$ where $c_{t}$ is time $t$ consumption of the one good in the model, $m_{t}$ is real balances held from $t$ to $t+1$, and $\beta$ $\varepsilon(0,1)$. As regards $u$, I assume that there is a satiation level of $m_{t}$, denoted $m^{*}$, such that for all $\left(c_{t}, m_{t}\right), u\left(c_{t}, m^{*}\right) \geq u\left(c_{t}, m_{t}\right)$. For $c_{t}>0$ and $m_{t} \varepsilon\left(0, m^{*}\right], u$ is differentiable, increasing (except that $\left.u_{2}\left(c_{t}, m^{*}\right)=0\right)$, strictly concave with $v\left(c_{t}, m_{t}\right) \equiv u_{2}\left(c_{t}, m_{t}\right) /$ $u_{1}\left(c_{t}, m_{t}\right) \rightarrow \infty$ as $m_{t} \rightarrow 0$ for any fixed $c_{t}$ and $v_{2}<0$. (The reader will be able to determine how the results noted below are affected if $u$ is assumed to be increasing in $m_{t}$ for all $m_{t}$ ) The agent is endowed with a constant amount of the consumption good at each date, denoted $w$, and enters date 1 with a positive nominal stock of money.

I will throughout be assuming competitive behavior. Here the agent maximizes discounted utility by choice of sequences for $c_{t}, m_{t}$ and $b_{t}$ (real loans at $t$ to be repaid at $t+1$ ) subject for $t \geq 1$ to 


$$
c_{t}+m_{t}+b_{t} \leq w+r_{t-1}^{m} m_{t-1}+r_{t-1} b_{t-1}
$$

taking as given the right-side of (5) for $t=1$ and positive and bounded sequences for $r_{t}^{m}$ and $r_{t}$--the real gross returns on money and loans, respectively. In addition, in order to keep the constraint set compact, I restrict the choices of $m_{t}$ and $b_{t}$ to be from bounded sets, which, however, can be chosen so that they turn out not to be binding.

I define an equilibrium to be sequences for $c_{t}, m_{t}, b_{t}$, $p_{t}, S_{t}, M_{t+1}, B_{t+1}$ for $t \geq 1$ that are appropriately bounded and nonnegative except for $b_{t}$ and $B_{t+1}$, such that those for $c_{t}, m_{t}, b_{t}$ are utility maximizing for the agent, (1) is satisfied, and the following market clearing conditions hold for $t \geq 1: c_{t}=w-D$, $m_{t}=p_{t} M_{t+1}$, and $b_{t}=p_{t} S_{t} B_{t+1}$. I will describe some stationary equilibria and their dependence on the portfolio of the government.

Subject to the bounds on $m_{t}$ and $b_{t}$ not being binding, the following standard first-order conditions are necessary and sufficient for a maximum to the agent's choice problem: (5) at equality and

$$
\begin{aligned}
& c_{t}: \beta^{t} u_{1}\left(c_{t}, m_{t}\right)=\lambda_{t} \\
& m_{t}: \beta^{t} u_{2}\left(c_{t}, m_{t}\right)=\lambda_{t}-\lambda_{t+1} r_{t}^{m} \\
& b_{t}: \quad 0=-\lambda_{t}+\lambda_{t+1} r_{t}
\end{aligned}
$$

where $\lambda_{t}$ is the positive multiplier associated with (5). Upon dividing (7) by (6) and using (8) to substitute for $\lambda_{t} / \lambda_{t+1}$, we see that (6)-(8) imply 


$$
v\left(c_{t}, m_{t}\right)=1-r_{t}^{m} / r_{t} .
$$

It follows by construction that there is a stationary equilibrium corresponding to any constants $m>0, r^{m}>0$ and $b$ that satisfy $v(w-D, m)=1-r^{m} / r\left((9)\right.$ with $\left.c_{t}=w-D\right),(3), r=1 / B$, and $m+b>D$. The inequality is the condition for a positive initial value of money, $p_{1}$, which is obtained from equation (2).

In general, if $D$ is too big, then there will not be such equilibria. Therefore, I proceed by assuming that there is a stationary equilibrium for $b=0$ and show that $a$ consequence is the existence of other, higher utility equilibria for some $b<$ 0 . Formally, I prove the following.

Proposition 1. Assume there is a stationary monetary equilibrium with $b=0$. Then, letting $\theta=b / m$, there is a stationary equilibrium for any $\theta \varepsilon(-a, 0]$ for some a $\varepsilon(0,1)$. Moreover, the maximum equilibrium values of $\mathrm{m}$ and of utility are decreasing in $\theta$ on this interval.

Proof. I begin by rewriting (3) as

$$
1-r^{m} / r=(r-1) / r+D /(m r)+[(r-1) / r] \theta \equiv g(m, \theta, r)
$$

where $\theta \equiv b / m$. Then, $m$ and $b$ satisfy $v(w-D, m)=1-r m / r,(3)$ and $r=1 / \beta$ if and only if they satisfy

$$
v(W-D, m)=g(m, \theta, 1 / \beta)
$$

I will treat $\theta$ as a parameter and will first consider solutions to (11) for $\theta \varepsilon(-1,0]$. 
In figure 1, I sketch $v(W-D, m)$ for $m \varepsilon\left(0, m^{*}\right]$, the relevant interval. Since $g(m, 0,1 / \beta)>0$, it follows that if there is a solution to (11) with $\theta=0$, there is a largest one and it is less than $\mathrm{m}^{*}$. Moreover, in the neighborhood of that solution, $\mathrm{g}_{1}$ $>v_{2}$. Since $g_{2}>0$ and since $g(m, \theta, 1 / \beta)>0$ for $\theta \varepsilon(-1,0]$, it follows that the existence of a solution for $\theta=0$ implies the existence of a solution for all such $\theta$ and that the maximum solution is decreasing in $\theta$.

I now consider the subset of these maximum solutions that satisfy $m+b>D$. In figure 2, I sketch the maximum solution to (11) as a function of $\theta$. The maximum solution for $\theta=0$ is shown as exceeding $D$ in accord with the hypothesis that there is a solution for $\theta=0$. Also sketched is the curve $m+b=D$ which is equivalent to $m=D /(1+\theta)$. The region to the right and above this curve satisfies the inequality $m+b>D$. It follows that the interval $(-a, 1]$ is as shown in figure 2 .

Note that since utility is increasing in $m$ for all solutions to (11), utility corresponding to $\left(c_{t}, m_{t}\right)=(w-D, \hat{m})$ is the least upper bound on utility consistent with stationary equilibria under our policies. Moreover, there are stationary equilibria that get arbitrarily close to this upper bound. By equation (2), arbitrary closeness to $\hat{\mathrm{m}}$ implies an initial value of money, $p_{1}$, that is arbitrarily close to zero. $\Delta$

With equilibria indexed by $\theta$, there seems to be a possibility of multiple solutions to (11) for a given $\theta$. However, it is easy to avoid this. Policy can be described directly in terms of a magnitude of $1-r^{m} / r=1-S$, where $S$ is a constant value of 
$S_{t}$. In other words, the policy that uniquely determines a given equilibrium $\mathrm{m}$ can be expressed by a choice of a nominal interest rate; the government simply announces a willingness to lend (and borrow) at a given nominal interest rate. Expressing policy this way does not, of course, get around the fact that there is no best policy. In particular, if $D=0$, then utility is increasing in $S$ for $S \varepsilon(B, 1)$, but a monetary stationary equilibrium does not exist for $S=1$ (a zero nominal interest rate).

\subsection{Cash-in-advance}

Here I use a model in which the representative agent again maximizes discounted instantaneous utility. Now, however, instantaneous utility depends on consumption of a (purchased) good, denoted $c_{t}$ at time $t$, and on leisure, denoted $w-y_{t}$ at $t$, where $w$ is the agent's constant endowment of labor measured in units of potential production and $y_{t}$ is time $t$ production. Thus, the agent has preferences given by $\sum_{t=1}^{\infty} \beta^{t} u\left(c_{t}, w-y_{t}\right)$, where $\beta$ $\varepsilon(0,1)$ and $u$ is increasing, strictly concave, and twice differentiable and $v\left(c_{t}, w-y_{t}\right) \equiv u_{2}\left(c_{t}, w-y_{t}\right) / u_{1}\left(c_{t}, w-y_{t}\right)$ satisfies $v\left(x_{1}, x_{2}\right)$ +0 as $x_{1} \rightarrow 0$ for any fixed $x_{2}>0$ and $v\left(x_{1}, x_{2}\right)+\infty$ as $x_{2}+0$ for any fixed $x_{1}>0$ and is increasing in $x_{1}$ and decreasing in $x_{2}$. The cash-in-advance feature of the model is that the agent cannot use the proceeds from selling production at date to finance purchases of the consumption good at date $t$. Instead, following Helpman [1981] and Lucas [1982], it is assumed that the agent faces the following three constraints:

$$
\tilde{m}_{t}+b_{t} \leq r_{t-1}^{m} m_{t-1}+r_{t-1} b_{t-1}
$$




$$
c_{t} \leq \tilde{m}_{t}
$$

$$
m_{t} \leq y_{t}+\left(\tilde{m}_{t}-c_{t}\right)
$$

The first of these is the constraint in a money-securities market which occurs at the start each of date. (Note that $\tilde{m}_{t}$ denotes the value of money held at the close of the securities market.) Afterward, shopping for the consumption good is undertaken subject to (13), while the selling of production and accumulation of money carried into period $t+1, \mathrm{~m}_{t}$, is undertaken subject to (14). Implicit in (14) is the assumption that the price faced while shopping is the same as that faced while selling, a symmetry condition. As above, to keep the constraint set compact, it will be assumed that the agent faces sequences of positive and bounded returns and is constrained to choose $\tilde{m}_{t}, b_{t}$, and $m_{t}$ sequences that are bounded.

A symmetric equilibrium for this model consists of sequences for $c_{t}, y_{t}, \tilde{m}_{t}, m_{t}, b_{t}, p_{t}, S_{t}, M_{t+1}, B_{t+1}$ for $t \geq 1$ that are appropriately bounded and that except for $b_{t}$ and $B_{t+1}$ are nonnegative, are such that $c_{t}, y_{t}, \tilde{m}_{t}, m_{t}$ and $b_{t}$ are utility maximizing subject to (12)-(14), (1) holds, and the following market clearing conditions hold: $c_{t}=y_{t}-D, m_{t}=p_{t} M_{t+1}$, and $b_{t}$ $=p_{t} S_{t} B_{t+1}$. I proceed as above to describe some stationary equilibria and their dependence on the government's portfolio.

Subject to the bounds on quantity choices not being binding, the following first-order conditions are necessary and sufficient for a maximum to the agent's problem: (12)-(14) and

$$
c_{t}: \quad B^{t} u_{1}\left(c_{t}, w-y_{t}\right)=\lambda_{2 t}+\lambda_{3 t}
$$




$$
\begin{aligned}
& y_{t}: \quad{ }^{t} u_{2}\left(c_{t}, w-y_{t}\right)=\lambda_{3 t} \\
& b_{t}:-\lambda_{1 t}+r_{t} \lambda_{1}, t+1 \\
& \tilde{m}_{t}:-\lambda_{1 t}+\lambda_{2 t}+\lambda_{3 t}=0 \\
& m_{t}: r_{t}^{m} \lambda_{1, t+1}-\lambda_{3 t}=0
\end{aligned}
$$

where $\lambda_{1 t}, \lambda_{2 t}$, and $\lambda_{3 t}$ are nonnegative multipliers associated with (12), (13), and (14), respectively. Upon eliminating the multipliers in (15)-(19), we obtain

$$
v\left(c_{t}, w-y_{t}\right)=r_{t}^{m} / r_{t}
$$

Here, again by construction, there is a stationary equilibrium in which (12)-(14) hold at equality corresponding to any constants $r^{m}$ $>0$ and $m=y>0$ that satisfy $v(y-D, w-y)=r^{m} / r<1, \quad(3)$, $r=1 / B$, and $m+b>D$.

In order to avoid making additional assumptions about $\mathrm{v}$, I will again assume the existence of a stationary equilibrium for $b=0$ and prove that a consequence is the existence of other stationary equilibria for $b<0$. In fact, the wording of Proposition 2 is identical to that of Proposition 1.

Proposition 2. Assume there is a stationary equilibrium with $b=0$. Then letting $\theta=b / m$, there is a stationary equilibria for any $\theta \in(-a, 0)$ for some a $\varepsilon(0,1)$. Moreover, the maximum equilibrium values of $\mathrm{m}$ and of utility are decreasing in $\theta$ on this interval. 
Proof. It is immediate that $y=m, r=1 / B,(3)$ and $v(y-D, w-y)=$ $\mathrm{r} / \mathrm{r}$ are satisfied for a given $\theta$ if an only if $m$ satisfies

$$
v(m-D, w-m)=1-g(m, \theta, 1 / \beta)=1-\beta D / m-(1+\theta)(1-\beta)
$$

Since $g(m, \theta, 1 / \beta)>0$ for any $\theta>-1$ (or $m+b>0)$, any solution of (21) consistent with $m+b>D$ implies $r^{m} / r<1$. Therefore, we can proceed essentially as we did for the money-in-the-utilityfunction model, by analyzing maximum solutions for $m$ to (21) that also satisfy $m+b>D$.

Figure 3 depicts the left and right sides of (21). Since $1-g(m, \theta, 1 / \beta)$ is decreasing in $\theta$, existence of a solution with $m>0$ for $\theta=0$ implies that there is at least one solution to (21) for any $\theta \varepsilon(-1,0) .^{3}$ It also follows that the maximum solution is larger the smaller is $\theta$.

These results imply that figure 2 is applicable to this model except that $\mathrm{m}^{*}$ must now be interpreted as the solution to $v\left(m^{*}-D, w-m^{*}\right)=1$ and the curve labeled maximum solutions to (11) must be relabelled to be such solutions to (21). This shows that there are solutions to (21) and $m+b>D$ for any $\theta \varepsilon(-a, 0)$ for some a $\varepsilon(0,1]$. Moreover, since the maximum solution to (21) is decreasing in $\theta$ on this interval and since $u(m-D, w-m)$ is increasing in $\mathrm{m}$ for $\mathrm{m} \varepsilon\left(0, \mathrm{~m}^{*}\right]$, it is immediate that utility corresponding to the maximum solution to (21) is decreasing in $\theta$. (As in the money-in-the-utility-function model, this maximum can be achieved by stating policy in terms of a nominal interest rate.) $\Delta$

Thus, both in the money-in-the-utility-function model and the cash-in-advance model, more government lending gives rise 
to a lower inflation rate (a higher real return on money) and a higher initial price level. In these models, the initial price level is irrelevant to anyone's welfare, while the higher real return on money is welfare improving.

\section{Overlapping Generations Models}

Overlapping generations models without bequest motives allow for a richer set of possible outcomes than the representative agent models because in them different policies generally give rise to distribution effects, at least across generations. One consequence is that even in very simple pure-exchange versions of such models steady-state real interest rates can depend on the government's portfolio. Moreover, as is well-known, in some versions, real interest rates can be negative. I will review simple versions in which rate-of-return dominance is produced by moneyin-the-utility-function, by cash-in-advance constraints, and by legal restrictions.

\subsection{Money-in-the-utility-function}

Consider a stationary, pure-exchange one-good per date overlapping generations model defined over dates $t \geq 1$ in which agents live for two periods. Each two-period lived agent has preferences given by $U\left(c_{1}, c_{2}, m\right)=u\left(c_{1}, c_{2}\right)+v(m)$, where $c_{i}$ is consumption in the ith period of life and $\mathrm{m}$ is real money holdings carried from the first period of life into the second. (The assumption that $\mathrm{U}$ is additively separable in this way simplifies the analysis.) I assume that $u$ is differentiable, increasing, and strictly quasi-concave with both $c_{1}$ and $c_{2}$ being normal goods, 
that $v$ is differentiable, that there exists $m^{*}>0$ such that $v\left(m^{*}\right)$ $\geq v(m)$ for all $m$ and that $v^{-}(m)>0$ for $m \varepsilon\left[0, m^{*}\right)$. Each such agent is endowed with $w_{i}>0$ units of the consumption good at the ith period of life. At $t=1$, each agent who is in the second period of life is endowed with $w_{2}$ units of the date 1 good and with $M_{1}>0$ units of money and wants to maximize consumption of date 1 good.

For any $t \geq 1$, a two-period lived agent can be viewed as choosing $\left(c_{1}, c_{2}, m, b\right)$, where $b$ is real lending, to maximize $U$ subject to

$$
\begin{aligned}
& c_{1}+m+b \leq w_{1} \\
& c_{2} \leq w_{2}+r_{t}^{m}+r_{t} b
\end{aligned}
$$

and nonnegativity constraints except on b. Since b is unconstrained, this pair of constraints is equivalent in how it constrains the arguments of $U$ to the following single constraint,

$$
c_{1}+c_{2} / r_{t} \leq w_{1}+w_{2} / r_{t}-m\left(1-r_{t}^{m} / r_{t}\right)
$$

The following first-order conditions and (24) at equality are necessary and sufficient for maximization of $U$ subject to (24):

$$
\begin{aligned}
& c_{1}: u_{1}\left(c_{1}, c_{2}\right)=\lambda_{t} \\
& c_{2}: u_{2}\left(c_{1}, c_{2}\right)=\lambda_{t} / r_{t} \\
& m: v^{\prime}(m)=\lambda_{t}\left(1-r_{t}^{m} / r_{t}\right)
\end{aligned}
$$

where $\lambda_{t}$ is the nonnegative multiplier associated with (24). 
As above, I will discuss how stationary equilibria depend on the portfolio of the government. Here, however, I will consider only $D=0$ and will only demonstrate that there are equilibria in which money balances are close to the satiation level $\mathrm{m}^{*}$. Note that with $\mathrm{D}=0$, a stationary equilibrium consists of scalars $\left(c_{1}, c_{2}\right), r, r^{m}, m, b$ and $p_{1}$ (all positive except for b), such that $\left(c_{1}, c_{2}, m\right)$ maximize $U$ subject to (24), such that (1) holds, and such that $c_{1}+c_{2}=w_{1}+w_{2}$. The following proposition considers two cases, the negative real interest case and the nonnegative real interest case.

Proposition 3. Let $D=0$. (a) If $u_{1}\left(w_{1}, w_{2}\right) / u_{2}\left(w_{1}, w_{2}\right)<1$, then there is an equilibrium with $m_{t}=m^{*}$ for all $t$. (b) If $u_{1}\left(w_{1}, w_{2}\right) / u_{2}\left(w_{1}, w_{2}\right) \geq 1$, then there are equilibria with $m_{t}=m<$ $\mathrm{m}^{*}$ and $\mathrm{m}$ arbitrarily close to $\mathrm{m}^{*}$.

Proof. For this model, the requirement that the equilibrium be monetary, $m+b>0$, is by (22), equivalent to $c_{1}<w_{1}$. This and market clearing, $c_{1}+c_{2}=w_{1}+w_{2}$, imply that any monetary stationary equilibrium is on the slope -1 line depicted in figure 4 northwest of the endowment.

(a) There is an equilibrium with $r=r^{m}=1$ and $\left(c_{1}, c_{2}, m\right)=\left(c_{1}^{*}, c_{2}^{*}, m^{*}\right)$, where $\left(c_{1}^{*}, c_{2}^{*}\right)$ is the unique solution to $u_{1}\left(c_{1}, c_{2}\right) / u_{2}\left(c_{1}, c_{2}\right)=1$ and $c_{1}+c_{2}=w_{1}+w_{2}$. The corresponding $b$ is chosen to satisfy (22) at equality. It follows then that (23) holds at equality, and, by summing (22) and (23), that (3) holds. The initial value of money is obtained from (2). 
(b) Let $\left(\bar{c}_{1}, \bar{c}_{2}\right)$ satisfy $\bar{c}_{1}<w_{1}, \bar{c}_{1}+\bar{c}_{2}=w_{1}+w_{2}$. Then, by assumption, $\bar{r}=u_{1}\left(\bar{c}_{1}, \bar{c}_{2}\right) / u_{2}\left(\bar{c}_{1}, \bar{c}_{2}\right)>1$, which implies that $\bar{c}_{1}+\bar{c}_{2} / \bar{r}<\bar{w}_{1}+\bar{w}_{2} / \bar{r}$. We now show that if $\bar{c}_{1}$ is sufficiently close to $w_{1}$, then for $\left(c_{1}, c_{2}, r\right)=\left(\bar{c}_{1}, \bar{c}_{2}, \bar{r}\right)$, there are corresponding constant values of $m_{t}$ and $r_{t}^{m}$ that satisfy (24) at equality and (27) and that these are an equilibrium. We proceed using figure 5 and letting $x_{t}=\left(1-r_{t}^{m} / \bar{r}\right)$. For fixed $\left(\bar{c}_{1}, \bar{c}_{2}, \bar{r}\right)$, the locus of pairs $\left(x_{t}, m_{t}\right)$ satisfying $m_{t}>0$ and (24) at equality is a rectangular hyperbola that approaches the axes as $\bar{c}_{1} \rightarrow w_{1}$. The locus of pairs satisfying (27) (and (25)) is as shown in figure 5. Therefore, as $\bar{c}_{1} \rightarrow w_{1}$, the loci intersect at an $m_{t} \rightarrow$ $m^{*}$. Given $m_{t}$ and $x_{t}, b$ is chosen to satisfy (22) at equality. As in part (a), it follows that (23) holds at equality. Then (22) and (23) imply that (3) holds.s

The argument used in part (b) could be used to show that any $\left(\bar{c}_{1}, \bar{c}_{2}\right)$ satisfying $\bar{c}_{1}+\bar{c}_{2}=w_{1}+w_{2}, \bar{c}_{1}<w_{1}$, and $u_{1}\left(\bar{c}_{1}, \bar{c}_{2}\right) / u_{2}\left(\bar{c}_{1}, \bar{c}_{2}\right) \equiv \bar{r}>1$ can be supported as an equilibrium provided that the locus determined by $v^{\prime}\left(m_{t}\right)=\lambda x_{t}$ is somewhere above that determined by $m_{t} x_{t}=\left(\bar{c}_{1}-w_{1}\right)+\left(\bar{c}_{2}-w_{2}\right) / \bar{r}$. Such a qualification did not arise in my discussion of the representative agent money-in-the-utility-function model, because there I simply assumed that an equilibrium with $b=0$ exists and then showed that there were equilibria with $b<0$. That kind of argument would apply here if $u$ were assumed to be such that $u_{1}\left(c_{1}, w_{1}+w_{2}-c_{1}\right)$ is decreasing in $c_{1}$.

Policies in this model are able to affect the real rate of interest because the equilibrium consumption allocation is not 
fixed by the given endowment. The presence of young and old at each date allows for distribution effects. These distribution effects, in turn, produce noncomparability among all the equilibria that produce nonnegative real interest rates. In particular, although the lifetime utility of each two-period lived agent is increasing for moves southeast along the line $c_{1}+c_{2}=w_{1}+w_{2}$ in figure 4 toward $\left(c_{1}^{*}, c_{2}^{*}\right)$ in case (a) or toward $\left(w_{1}, w_{2}\right)$ in case (b) the consumption of time 1 good by the initial old person is decreasing. This reduced consumption is brought about by a lower value of the initial money stock, which in this model affects someone's utility.

\subsection{Cash-in-advance}

In a recent paper, Woodford [forthcoming] presents an overlapping generations, cash-in-advance model. The model is one of three-period lived overlapping generations with many identical agents per generation. Each agent has preferences given by $u\left(w-y, c_{1}, c_{2}, c_{3}\right)$, where $c_{i}$ is consumption of a (purchased) good in the ith period of life, $w$ is an endowment of leisure in the first period of life, and $y$ is output of a produced good in that period, a produced good which the individual does not consume. There are no intertemporal technologies. For my purpose, it is enough to suppose that $\mathrm{u}$ is increasing and strictly quasi-concave.

The cash-in-advance aspect of the model is the same as that in the representative agent cash-in-advance model described above. In particular, at each date, trade proceeds subject to $(12)-(14)$. That is, first there is a market in which money and loans are traded subject to (12). Then shopping for the consump- 
tion good occurs subject to (13), while sales of the produced good and acquisition of money for the next period occurs subject to (14). Although young, middle-aged and old are subject to these constraints at each date, the endowment and age patterns of the participants imply somewhat special patterns of demands.

For young people, the right-side of (12) is zero. Therefore, because of (13), they must incur debts or borrow at least enough to finance their desired consumption when young. Old people cannot borrow and do not want to lend. Thus, any borrowing by the young must be matched by lending by the middle-aged or the government.

I will again impose $D=0$ and will mainly discuss the role of government lending in supporting the allocation that maximizes sustainable life-time utility and the consequences for steady-states of alternative policies. Here, however, it must be remembered that steady-states are not equilibria except for particular initial conditions. In particular, if this economy is defined over dates $t \geq 1$, a specific steady-state is an equilibrium only for a specific corresponding initial distribution of wealth among the people who are middle-aged and old at $t=1$ and, in the case of nonseparable utility, a particular realized $\left(y, c_{1}\right)$ for the middle-aged.

Let $\left(y_{1}^{*}, c_{1}^{*}, c_{2}^{*}, c_{3}^{*}\right)=z^{*}$ be the solution to the following problem: maximize u subject to $y=c_{1}+c_{2}+c_{3}, y \varepsilon[0, w]$, and $c_{i}$ $\geq 0$. Also, let $M$ be the nominal stock of outside money, the stock that would exist if there were no government borrowing and lending, and let $p^{*}$ be such that $p^{*} M=c_{2}^{*}+2 c_{3}^{*}$. If the government 
stands ready to borrow and lend at a zero nominal interest rate, then it is easy to see that $p_{t}=p^{*}, r_{t}=1$, and $z^{*}$ is a steadystate for the model. At zero nominal and real interest rates, the market constraints facing a young person--(12)-(14) at each period of life--are equivalent to $y \geq c_{1}+c_{2}+c_{3}$. Therefore, $z^{*}$ is a utility maximizing choice. If repeated date after date, such a choice also clears the goods market. It turns out that there are many individual portfolios that support $z^{*}$ and are market clearing. One of these is to have each young person borrow $c_{1}^{*} / p^{*}$ units of money from the government (repaying when middle-aged) and to have each middle-aged person do no borrowing and lending. Another possibility is to have each young person borrow $c_{3}^{*} / \mathrm{p}^{*}$ from a middle-aged person and borrow $\left(c_{1}^{*}-c_{3}^{*}\right) / p^{*}$ from the government. More generally, the amount of government lending can be anything greater than or equal to this last quantity.

If the government does not lend and if $c_{1}^{*}<c_{3}^{*}$, then, as just explained, $p_{t}=p^{*}, r_{t}=1$, and $z^{*}$ is a steady-state. If $c_{1}^{*}$ $>c_{3}^{*}$, then $p_{t}=p^{*}$ and $r_{t}=1$ cannot be a steady-state with no government lending. Faced with such returns, desired lending by a middle-aged person is no greater than $c_{3}^{*} / p^{*}$, while desired borrowing by a young person is no less than $c_{1}^{*} / \mathrm{p}^{*}$. If there is to be a steady-state under these circumstances it must have a constant value of money $\left(r_{t}^{m}=1\right)$ and a constant $r_{t}>1$, implying a positive nominal interest rate. With $r_{t}^{m}=1$, the higher is $r_{t}$, the more expensive is $c_{1}$ in terms of leisure and the cheaper is $c_{3}$ in terms of leisure; the terms of trade between $c_{2}$ and leisure is determined by $r_{t}^{m}$. In particular, as in the representative agent cash- 
in-advance model, at any positive nominal interest rate, agents see themselves as being able to trade a unit of leisure for less than a unit of current consumption.

Since any steady-state satisfies $y=c_{1}+c_{2}+c_{3}$, the lifetime utility implied by any steady-state different from $z^{*}$ is less than that of $\mathrm{z}^{*}$. This conclusion is analogous to what we found in the money-in-the-utility-function, overlapping generations model. There, however, each steady-state was a stationary equilibrium for the same arbitrary initial condition, which allowed us to conclude that nonnegative real interest rate steadystates are noncomparable equilibria. Here, the analogous result would be that starting from a given initial condition, different policies give rise to noncomparable equilibria. I suspect that this is the case for policies that give rise to equilibria that converge to steady-states with nonnegative nominal and real interest rates.

Finally, the Woodford model can easily be converted to one that has implications similar to the nonnegative interest-rate version of the money-in-the-utility-function, overlapping generations model. If the middle-aged, in addition to the young, are endowed with productive leisure, then the model can be a naturally nonnegative real interest rate economy. In such a version, a zero nominal interest rate could not be achieved by government lending. In this regard, such a version would resemble the representative agent cash-in-advance model. 


\subsection{Legal restrictions}

In several papers, the overlapping generations intertemporal framework has been combined with a legal restrictions explanation of money dominated in rate of return (see Wallace [1983] for example). It turns out that for a given set of legal restrictions that are consistent with rate-of-return dominance, legal restrictions models have implications for the role of different government portfolios that are similar to those of models which rely on natural explanations for rate-of-return dominance. I will discuss this similarity by comparing the implications of two models that use the legal restrictions explanation to the implications of the money-in-the-utility-function and cash-in-advance overlapping generations models described above.

Bryant and Wallace [1984] describe a model basically like the money-in-the-utility-function overlapping generations model described above except that money is not an argument of the utility function. The legal restriction in their model is that members of a single generation, who are assumed identical, cannot intermediate among themselves and, by so doing, share large denomination bonds issued by the government. Since they cannot, arbitrage does not rule out the possible coexistence of zero nominal interest money and positive interest bonds.

Bryant and Wallace show that if a positive deficit can be financed with zero government borrowing, $b_{t}=0$, then there are Pareto superior stationary equilibria that involve the issue of bonds. The bonds, as noted above, are large denomination securities whose presence along with that of divisible money implies 
that savers face a nonconstant return schedule on savings, a schedule which is increasing in the amount saved. It is this feature which allows schemes with bonds to dominate the solutions with money financing alone. Such Pareto superior equilibria have yields on bonds that are negative, but higher than the yield on money. The equilibria are Pareto superior in that they give higher utility to each two-period lived person and also give more consumption to the initial old by way of a higher value of initial money holdings. The latter comes about through higher equilibrium values of $m+b$ in equation (2).

I suspect that the same kind of result can show up in versions of the money-in-the-utility-function and cash-in-advance versions of the overlapping generations model. In the money-in the-utility-function model, a comparable situation would be one in which for a positive net-of-interest deficit and no government borrowing, there is an equilibrium with a negative real interest rate. Then, there will be stationary equilibria with some government borrowing and with both higher utility and additional savings by each two-period lived person. The latter implies additional consumption by the initial old. Matters are less clear-cut in Woodford's model because steady-states are not equilibria for given initial conditions. However, with a positive net-of-interest deficit and without government borrowing, that model can have steady-states with a negative real interest rate on securities. It would then seem that there are other steady-states with some government borrowing that give higher utility to each three-period lived person. The crucial common feature at work is that some bonds can be sold at a negative real interest rate. 
Sargent and Wallace [1982] look at a somewhat different legal restriction in a model with a special kind of within generation diversity. They assume that the legal restriction prevents private borrowers from issuing claims in a small size--a kind of denomination restriction--and that there is a group of poor savers in the economy who are thereby restricted to holding government issued money. There are other savers who are not constrained by the restriction. They along with private borrowers interact in a private credit market which for some parameters and some policies gives rise to a positive nominal interest rate in a credit market that is completely separate from the market for government issued money.

In a stationary version of that model (the original version had a periodic endowment for borrowers), it is easy to show that different equilibria with differing real returns on both money and bonds can be generated by policies in the class I have been examining. ${ }^{4}$ Government lending tends to reduce the real interest rate in the credit market and to increase the real return on money. These effects are accompanied by the obvious distribution effects on participants in these markets; the greater the amount of government lending the better off are borrowers and moneyholders and the worse of are lenders in the credit market. Whether a policy in this class can eliminate the difference in returns in the two markets depends, as in the models above, on whether the economy is or is not a nonnegative interest rate economy . 
The effects of different policies that show up in the Sargent-Wallace model would also show up in versions of money-in the-utility-function and cash-in-advance overlapping generations models with diversity so that some people end up borrowing and some lending at most interest rates. Thus, the important role of the government's portfolio in the Sargent-Wallace model should not be attributed to the legal restriction feature of the model. It should, instead, be attributed to the presence of diversity, which allows for a rich set of distribution effects.

\section{Concluding remarks}

I have examined a small set of models from the perspective of their implications for policies in a particular class. Here I first comment briefly, again, on the policies examined and then on the models.

Examining alternative government portfolios holding the real net-of-interest deficit constant is one way to discuss tile role of monetary policy while holding fiscal policy constant. An alternative that is, perhaps, more standard involves holding constant the real gross-of-interest deficit. According to that alternative, any change in the government's portfolio is accompanied by a change in direct taxes that offsets the implied change in the flow of government interest payments. If lump-sum taxes can be levied, then that kind of experiment is a very simple one. In fact, then open-market operations are irrelevant in the models examined above in the sense that given an equilibrium with some government borrowing or lending, there is another equilibrium with no government borrowing or lending and a different stream of 
lump-sum taxes that leaves unaffected all the variables that affect welfare. If, however, lump-sum taxes are not permitted, then such an experiment is not simple. But, the simplicity of holding the net-of-interest deficit constant should also be qualified. If there are direct taxes that are being held fixed in the background, then it would seem that those taxes can only be lumpsum taxes; if there were other taxes, their effects and the revenue they raise would depend on the government's portfolio. Subject to that qualification, the class of policies I have examined amounts to one way of isolating the role of the government's portfolio. In general, it is not possible to study monetary policy in the sense of open-market operations in isolation from fiscal policy.

The models examined above share two features which make them convenient for the analysis of open-market policies: money and bonds are distinct assets and there is a centralized market in money and bonds. Obviously, in models in which money and bonds are not distinct assets, open-market operations do not matter at all. And, no less obviously, in models without a centralized market in which money and bonds are traded, it is problematical what an open-market operation is. Although we seem to "see" both features--money and bonds being distinct and markets in which they are traded--there are reasons to be skeptical about the coincidence of these features in the models examined above. ${ }^{5}$

A long-standing point of view in monetary theory is that the role of "money" is to be understood in the context of settings in which trade or exchange is difficult to accomplish. Such 
difficulty is implicit in the notion of an absence-of-double-coincidence-of-wants, a notion which presumes something like pairwise, isolated meetings, rather than centralized markets. Consistent with that point of view, it is useful to conceive of a spectrum of alternative models or environments ranging from ones in which exchange is very difficult to accomplish (see Harris [1979], for example) to ones to where exchange is accomplished so easily that money and bonds cannot be distinct assets (see Wallace [1981], for example).

There should be skepticism about money-in-the-utilityfunction and cash-in-advance models because they seem to adopt some features from environments where exchange is difficult--the distinct role of "money"--and some features from environments in which exchange is easy to carry out--the centralized market in "money" and bonds. The few explicit attempts we have to study models in which exchange is difficult to accomplish (Harris [1979], Townsend [1980], Freeman [1985]) do not display both features.

The legal restrictions theory is in part inspired by such findings and by the related failure of the money-in-theutility-function and cash-in-advance models to address the following kinds of questions. Is the "money" in the money-in-the-utility-function model necessarily a government supplied object or could it instead be a privately issued object? In a cash-inadvance model, what prevents private arrangements in the securities market from supplanting the need for government issued money? These questions are pertinent because when those models 
give rise to a positive nominal interest rate, there seem to be profits to be made by private intermediation that takes the form of lending in the securities market and borrowing by issuing claims that compete with the zero interest government currency in the model. The legal restriction theory takes the extreme view that such privately supplied claims could compete perfectly with government supplied money. There is skepticism about the theory because it asserts that the relevant model is the extreme one in which exchange is accomplished so easily that money and bonds cannot be distinct, except insofar as explicit legal restrictions interfere.

All such skepticism aside, the implications for openmarket operations of the models examined above follow from the fact that in all those models the government-central bank has a monopoly on money. Subject to two qualifications, all the models say that it should supply that money cheaply by lending it at a low nominal interest rate. By doing that, it, in effect, is able to replace outside money which does not bear interest by inside money that does. One qualification concerns the net-of-interest deficit. If there is such a deficit, then the requirement that it be financed limits the extent to which the replacement can be accomplished, because it requires that the outside money be taxed. The other qualification concerns distribution effects, which were discussed above.

Finally, as regards the potential cyclical role of monetary policy, we have seen that variations in the government's portfolio holding the net-of-interest deficit constant affect real 
rates of returns. Thus, there is scope for different deterministic policies in that class to have cyclical effects. That scope is limited in the prototype models examined above because, for the most part, those were pure-exchange models. However, given that real returns can be affected in such models, it is obvious that production will respond to such policies in more general models. (Such a response is present in the cash-in-advance model.) Thus, these models provide no basis for taking as a kind of benchmark that alternative deterministic monetary policies are neutral. 
${ }^{1}$ For a discussion of some of the consequences of alternative specifications, see Waldo (1985).

${ }^{2}$ This class includes policies in which the government attempts to finance interest on money through earnings on its portfolio. See Friedman (1960) and Sargent and Wallace (1985).

${ }^{3}$ Notice that the only role of the hypothesis of Proposition 2 (existence for $b=0$ ) is to assure that the function $1-g(m, 0,1 / B)>v(m-D, w-m)$ for some $m>D$. Since at $m=D$, $1-g(m, 0,1 / \beta)=0$ and has a negative second derivative with respect to $\mathrm{m}$ (as shown in Figure 3), that hypothesis could be replaced by assumptions on the shape of $\mathrm{v}$ in the neighborhood of $v(0, w-D)--$ for example, the assumption that $v^{\prime \prime}>0$.

${ }^{4}$ The original version can be used to study a policy within the class of those studied here in which the central bank eliminates a deterministic fluctuation in the nominal interest rate (a seasonal) and earns zero on average on its portfolio.

${ }^{5}$ Not everyone "sees" money and bonds being distinct and a centralized market in which they are traded. One often comes across the comment that in some countries open-market operations cannot be conducted because there is no market in which money and bonds are traded. 


\section{References}

Bryant, John B. and Wallace, Neil (1984). A price discrimination analysis of monetary policy. Review of Economic Studies 51 (April): 279-88.

Freeman, Scott (1985). Transactions costs and the optimal quantity of money. Journal of Political Economy 93 (February) 146-57.

Friedman, Milton (1960). A Program for Monetary Stability (Fordham University Press, New York).

Harris, Milton (1979). Expectations and money in a dynamic exchange model. Econometrica 47 (November): 1403-19.

Helpman, Elhanan (1981). An exploration in the theory of exchange rate regimes. Journal of Political Economy 89 (October): 865-90.

Lucas, Robert E., Jr. (1982). Interest rates and currency prices in a two-country world. Journal of Monetary Economics 10: $335-360$.

Sargent, Thomas and Wallace, Neil (1982). The real-bills doctrine versus the quantity theory: A reconsideration. Journal of Political Economy 90 (December): 1212-36. . (1985). Interest on Reserves. Journal of Monetary Economics 15: 279-90.

Townsend, Robert M. (1980). Models of money with spatially separated agents. In Models of monetary economies, ed. J. Kareken and N. Wallace, pp. 265-303. Minneapolis: Federal Reserve Bank of Minneapolis. 
Waldo, Douglas (1985). Open market operations in an overlapping generations model. Journal of Political Economy 93 (December) $1242-57$

Wallace, Neil (1981). A Modigliani-Miller theorem for open-market operations. American Economic Review 71 (June) 267-74. (1983). A legal restrictions theory of the demand for "money" and the role of monetary policy. Federal Reserve Bank of Minneapolis Quarterly Review 7 (Winter): 1-7. Woodford, Michael (forthcoming). Credit policy and the price level in a cash-in-advance economy. In New approaches in monetary economics, ed. W. Barnett. Massachusetts: Cambridge University Press. 
Figure 1

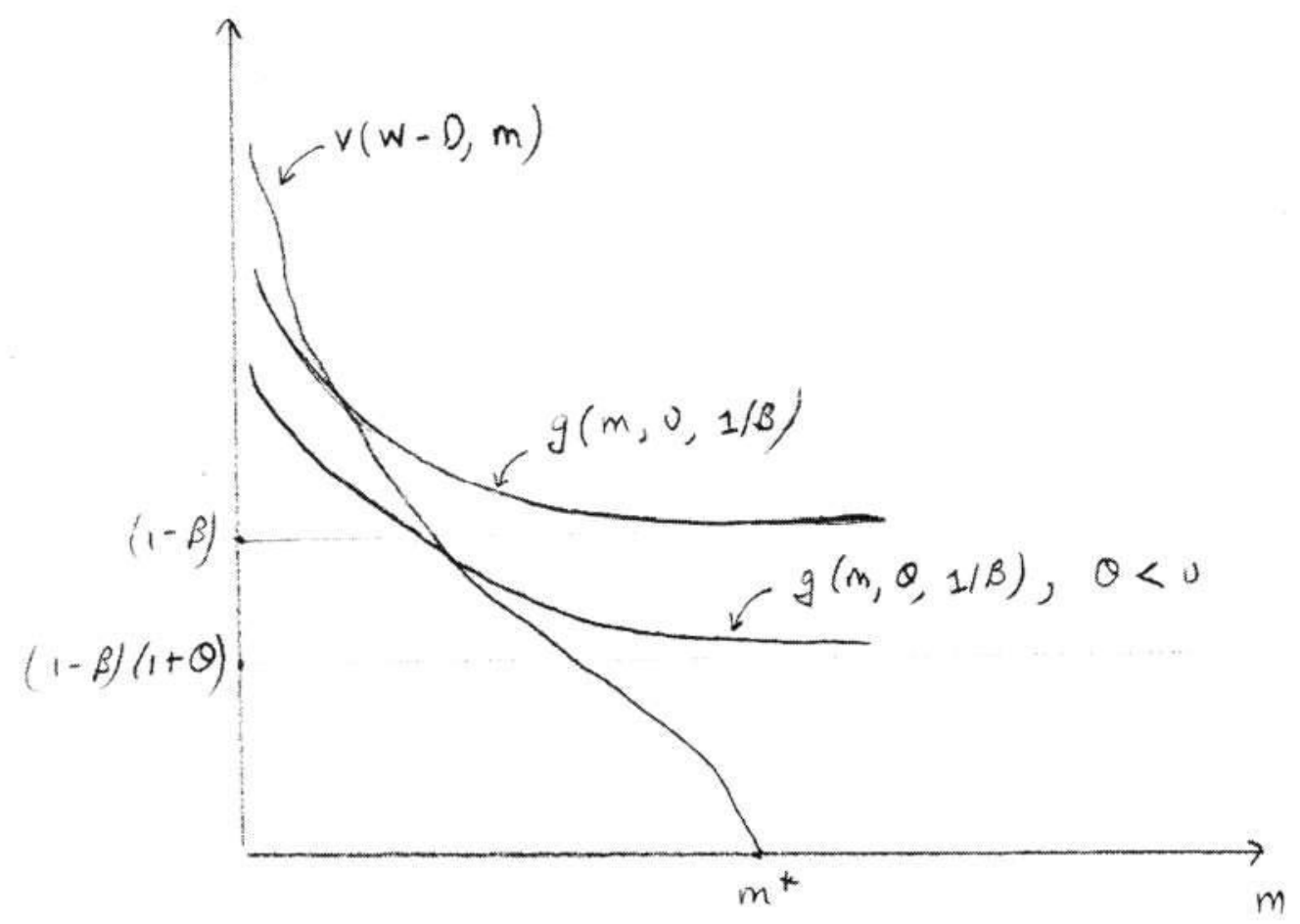


Figure 2

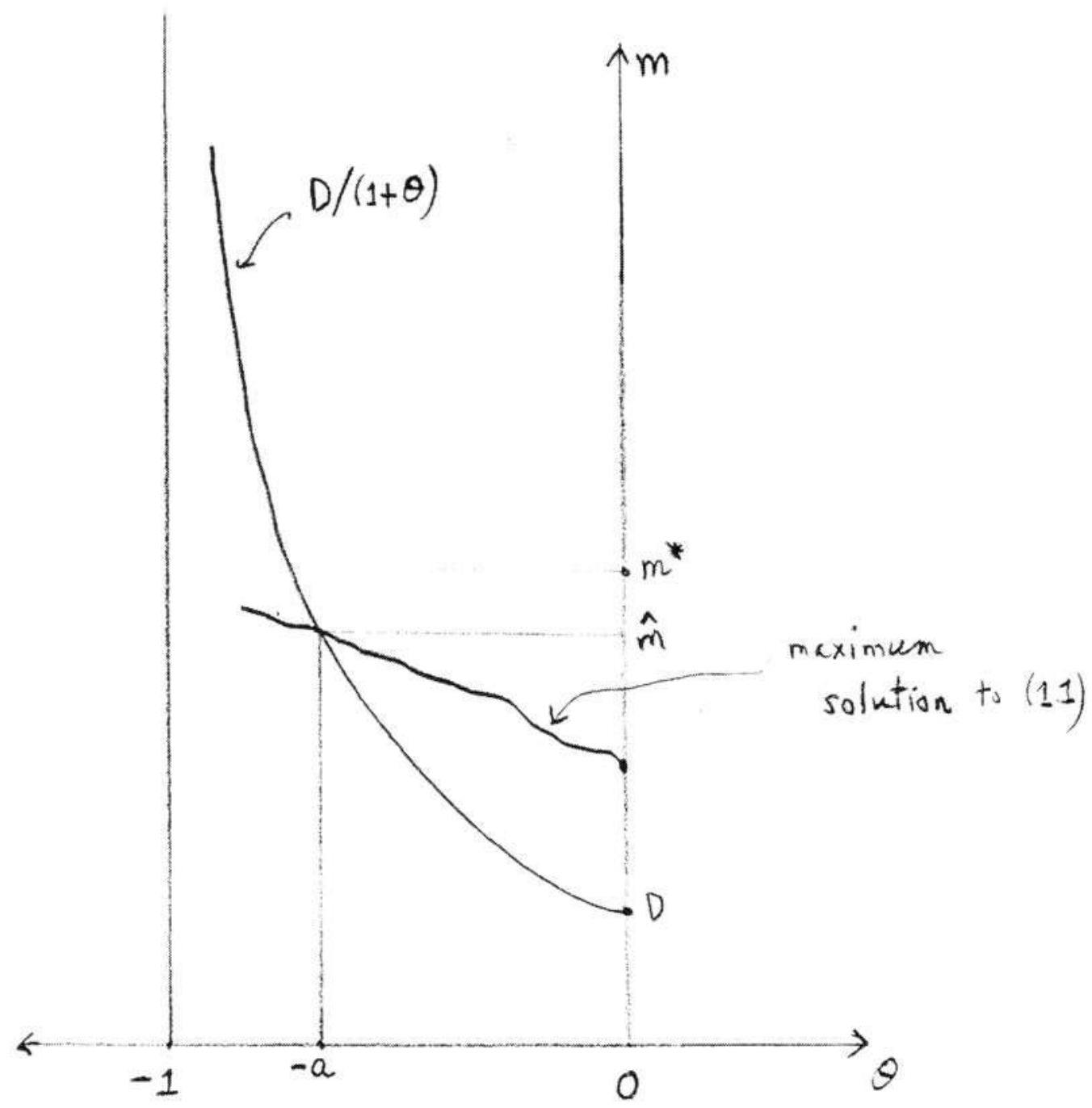


rigure 3

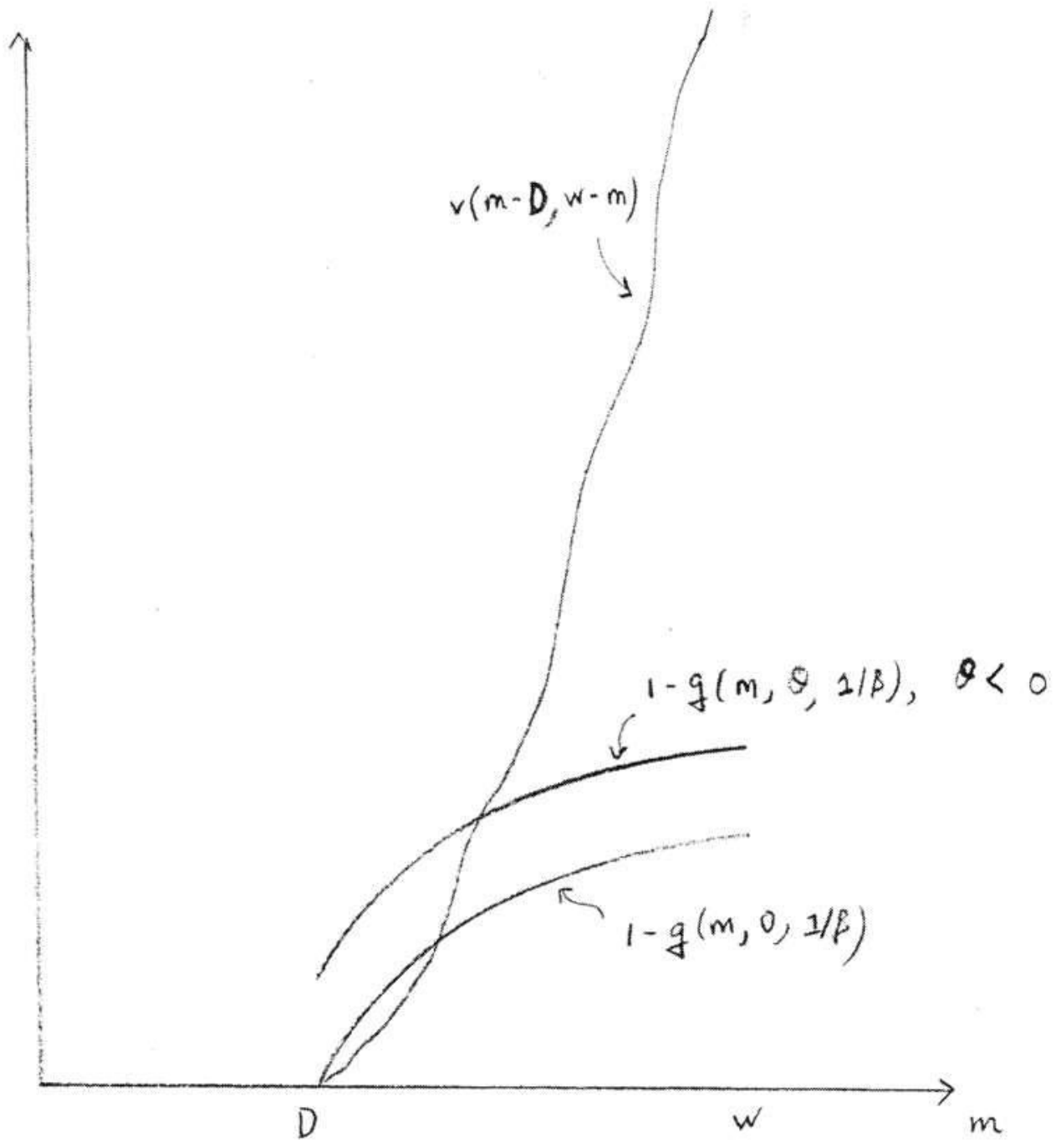


Figuve 4

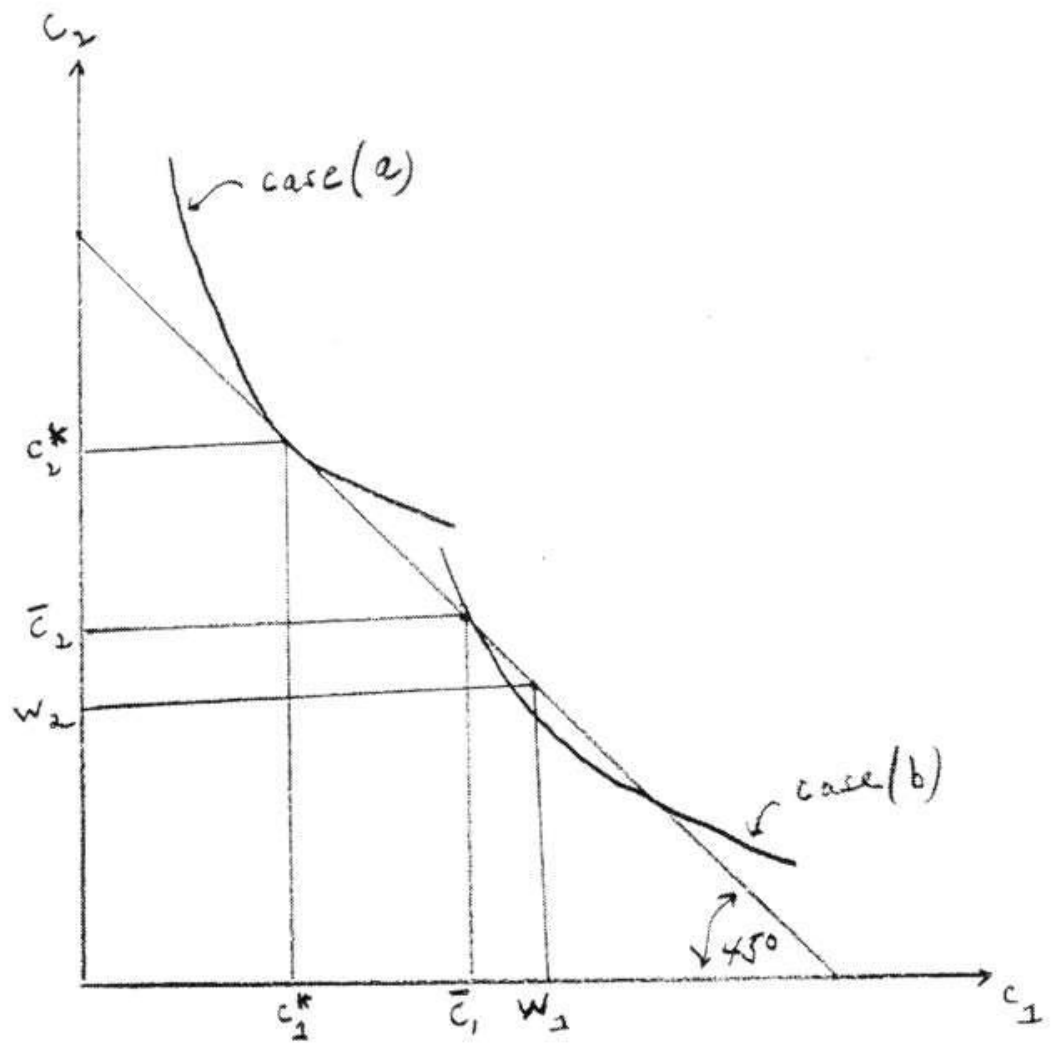


Figures

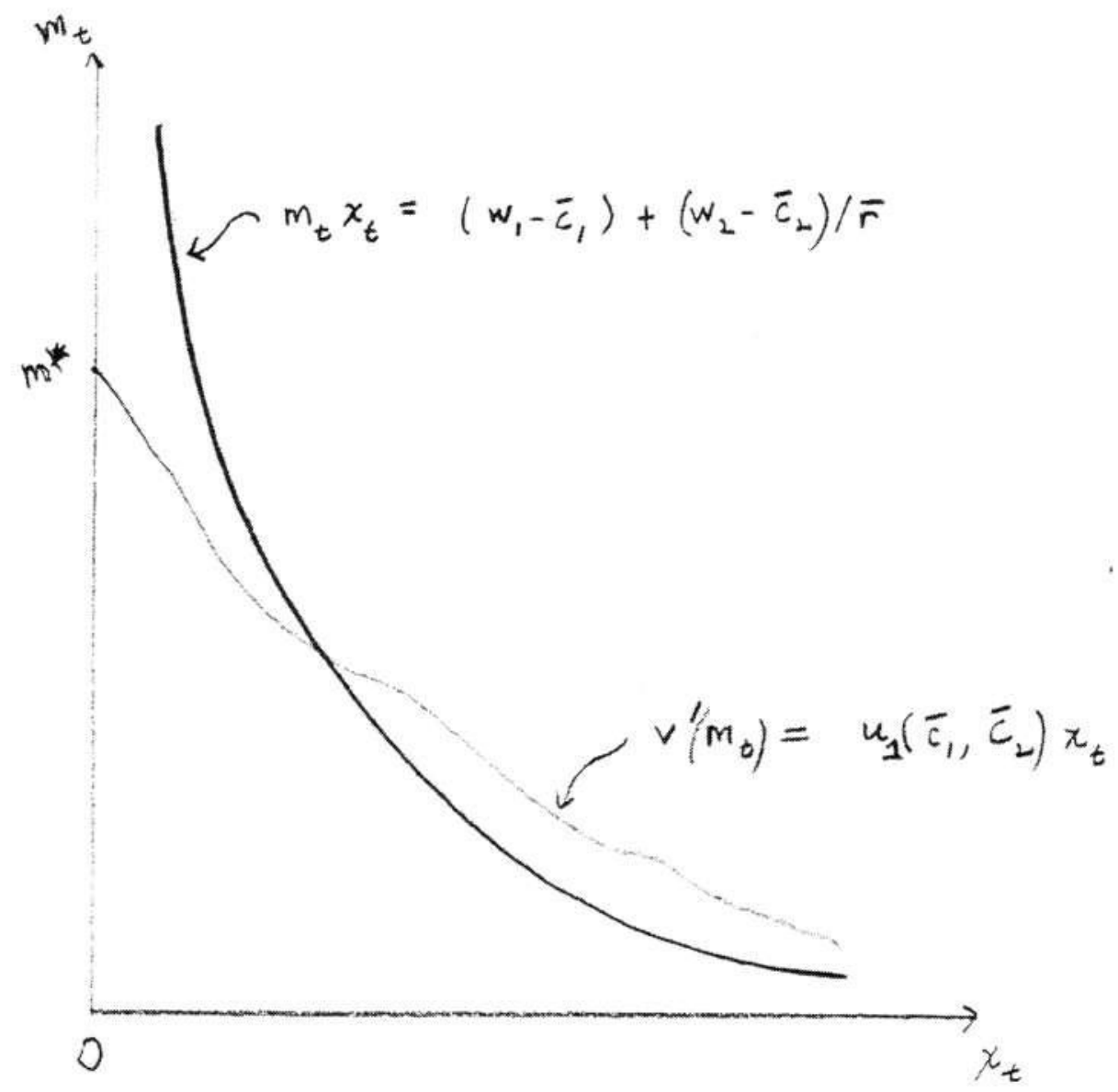

